\title{
Socio-economic development of fishers in Andhra Pradesh and Telangana states in India
}

\author{
KUPPUSAMY PONNUSAMY, R. SENDHIL*AND M. KRISHNAN \\ ICAR-Central Institute of Brackishwater Aquaculture, Chennai - 600 028, Tamil Nadu, India \\ "ICAR-Indian Institute of Wheat and Barley Research, Karnal - 132 001, Haryana, India \\ e-mail: ponnusamyk@hotmail.com
}

\begin{abstract}
A study was conducted across Andhra Pradesh and Telangana states among 647 fisher households comprising five major sectors viz., brackishwater, freshwater, reservoir and marine fisheries as well as procurement and marketing sectors to understand the level of socio-economic development of fishers. Fishers development index (FDI) was constructed based on health, income and literacy dimensions. Analysis of data indicated that the literacy level was highest among marine fishers (51.45\%), followed by brackishwater aquaculture $(45.61 \%)$ and fish procurement and marketing sector $(36.26 \%)$. Fishers in coastal areas tend to have better access to education than the fishers of inland water bodies. Incidence of common diseases (annual frequency) was more in the brackishwater aquaculture relative to other sectors in the study region. The position of educational and health status of fishers warrants a strong need to improve the access of fishers to health related services for overall development. High income from the marine sector and a relatively higher weightage (37\%) to the income dimension played a major role for its FDI score. Freshwater aquaculture took the top score in health, while reservoir fisheries ranked first in literacy. A multi-dimensional approach would enhance the income and employment generation of the fishers to match with the development of the rest in the society.
\end{abstract}

Keywords: Education, Fishers, Fishers development index, Health, Income

Fisheries is an important sector in India and plays an imperative role for livelihood security and socio-economic development of the country by supplementing family income, generating gainful employment and providing nutritious food to millions of rural poor (Ayyappan and Biradar, 2004). The sector contributed about $0.83 \%$ to the overall GDP in 2007-08 and $4.75 \%$ of the agricultural GDP in 2012-13 witnessing rapid strides in terms of production in the recent past (MoF, 2015). The turnover has reached to the tune of ₹780 billion in 2012-13 from ₹90 billion in 1993-94 indicating a nine-fold increase during the period (Sathiadhas et al., 2014). According to Livestock Census (2003), as many as 14.49 million persons in the country depend on fisheries sector for their livelihood (DADF, 2003). In India, fisheries sector contributes substantially to foreign exchange earnings through seafood exports and about 910 million of the population is projected to include fish in their diet by 2020 (Rao et al., 2011).

Among the agriculture and allied sectors, the fisheries sector has the weakest database on labour and income statistics including off-season livelihood options. This limits the planners to structure new schemes suitable for welfare of fishers/fish farmers, for want of ready availability of commonly used socio-economic indicators in the economics parlance like "people below poverty line", "physical quality of life index" and "mandays employed per annum". Hence a comprehensive study on all fisheries sectors involving socioeconomic data of the population assumes greater significance for promoting the interests of fishers.

Literacy, income and health are interlinked for the overall development of an individual's personality and socio-economic development of the society (Sathiadhas et al., 2014). But there is a lack of inclusive database on these three parameters which would facilitate ascertaining the status of fisherfolk in India. The composite states of Andhra Pradesh and Telangana represent an important stake in fisheries contributing a significant share to the national product. In this backdrop, the present study is an attempt to assess the development of fishers in Andhra Pradesh and Telangana by analysing their status in literacy, income and health. The outcome of the study is expected to help administrators, policy makers, researchers and academicians in framing strategies for inclusive growth and development of fishers.

The study sourced primary data by surveying 647 fisher households across the coastal regions of Andhra Pradesh and Telangana states comprising five major sectors viz., brackishwater aquaculture (shrimp farming), freshwater aquaculture, reservoir fisheries, fish procurement and marketing and marine fisheries (Table 1). Respondents were interviewed on their socio-economic and personal profile with more emphasis on health, income and educational status. 
Table 1. Composition of the sample households (number)

\begin{tabular}{lll}
\hline Sector & Selected districts & No. of households \\
\hline Brackishwater aquaculture (shrimp farming) & Krishna & 100 \\
Freshwater aquaculture & Krishna & 50 \\
Reservoir fisheries & Warangal and Khammam & 50 \\
Fish procurement and marketing & Visakhapatnam & 197 \\
Marine fisheries & Visakhapatnam & 250 \\
Total & & 647 \\
\hline
\end{tabular}

Present study utilised conventional tools and techniques like tabular analysis, frequency, percentage, ANOVA and arithmetic mean for analysing the health, income and educational status of fishers. The study also developed a methodology to rank the development status of fishers through a composite fishers development index (FDI). Three dimensions viz., health, income and literacy were used to construct the composite index for different sectors following the UNDP approach for estimating the human development index (Jhingan, 2012). Under literacy variable, two indicators were considered viz., literacy rate and gross enrolment ratio (upto primary). Performance in each dimension has been expressed as a value between 0 and 1 by applying the normalisation formula:

$$
\text { Dimension index }=\frac{(\text { Actual value }- \text { Minimum value })}{(\text { Maximum value }- \text { Minimum value })}
$$

Later, weights were assigned for each dimension based on experts' opinion collected by the authors (Health: 33\%, Literacy: 30\% and Income: 37\%). Finally, the sectors were divided into three relative categories based on the estimated composite FDI score adopting the approach of Ayyoob et al. (2013).

$$
\begin{array}{ll}
\text { Highly Developed } & =\text { FDI }>(\text { Mean }+0.5 \sigma) \\
\text { Moderately Developed } & =(\text { Mean }-0.5 \sigma)<\text { FDI }<(\text { Mean }+0.5 \sigma) \\
\text { Less Developed } & =\text { FDI }<(\text { Mean }-0.5 \sigma)
\end{array}
$$

Perusal of the fisher's age profile indicated that majority of the respondents across the study region ranged between 36 and 55 years and most of the households had 2 to 4 family members. Education is one of the important variables that increases the awareness and understanding of the interdependent and imbalanced functions of the society in which the fishers live. Hence, the literacy level of the family members was considered as an essential dimension towards their development. Analysis on the literacy profile indicated that a significant number of fisher's family members were illiterate (Table 2). It was highest in the case of marine fisheries $(51.45 \%)$ followed by brackishwater aquaculture $(45.61 \%)$ and fish procurement and marketing sector (36.26\%). Test of significance (ANOVA) analysis indicated that there existed a significant difference in literacy profile between sub-sectors. Among the literates, majority of the family members across all sectors were educated up to the secondary school level. However, in reservoir fisheries category, the family members did not pursue their education beyond primary level. This indicates that the fishers belonging to coastal areas who were engaged in marine fishing had better access to education than the fishers engaged in traditional fishing activities in inland water bodies such as reservoir fisheries. This demands special attention of the government for improving their educational access.

On the educational front, analysing the information on continuing education/dropping out of respondents, it was found that a considerable number of fisher family members were unable to pursue their educational aspirations. This was clearly evident in the sub-sectors where cash flow is relatively higher, such as brackishwater aquaculture and marine fisheries. However, a grim situation has been noticed in reservoir and freshwater aquaculture sub-sectors. This warrants for policy intervention in sectors where drop-out rate is high.

\begin{tabular}{|c|c|c|c|c|c|c|}
\hline \multirow{2}{*}{ Sector } & \multirow{2}{*}{ Total } & \multirow{2}{*}{ Illiterate } & \multirow{2}{*}{ Literate } & \multicolumn{3}{|c|}{ Literate } \\
\hline & & & & Primary & Secondary & Collegiate \\
\hline Brackishwater aquaculture (shrimp farming) & 421 & 192 & 229 & 62 & 137 & 30 \\
\hline Freshwater aquaculture & 142 & 23 & 119 & 29 & 77 & 13 \\
\hline Reservoir fisheries & 120 & 40 & 80 & 80 & - & - \\
\hline Fish procurement and marketing & 593 & 215 & 378 & 56 & 287 & 35 \\
\hline Marine fisheries & 1001 & 515 & 486 & 237 & 217 & 32 \\
\hline ANOVA & F value: $16.68^{* * *}$ & & & & & \\
\hline
\end{tabular}

Incidence of common diseases in the present and past indicated that fever/flu and body aches were the most

Table 2. Literacy profile of the respondent family members (No.)

\footnotetext{
${ }^{* * *}$ indicate significant difference among sub-sectors in literacy at $1 \%$ level of probability
} 
recurring ones across all sectors of fisheries (Table 3). Further, the study indicated that the incidence of common diseases (annual frequency) was more in the brackishwater aquaculture (shrimp farming) relative to other sectors in the study region. However, there is no reporting of special ailments such as cardiac failure, tuberculosis (TB), anaemia, diabetes, blood pressure, thyroid related ailments, sinusitis and AIDS during the study period as well as in the past. It is also to be noted that medical care through primary health centres and hospitals is available within a radius of $6 \mathrm{~km}$ with the exception for fishers engaged in brackishwater aquaculture (shrimp farming) who have to travel long distances to places like Machilipatnam and Vijayawada for hospital services. This also supported the fishers' response that they did not find any difficulty to access medical services in and around their location. It is interesting to note that the lifestyle diseases which are emerging as a major burden in the middle class families are found to be absent among the respondents. This indicates that regular fish consumption can result in warding off major lifestyle diseases. Despite the poor educational status of fishers, their health status appeared to be relatively better. However, there is a strong need to improve the access of fishers to health related services for overall development.

Income profile of respondents indicated that marine fishers earned the maximum income (₹11,223.08 per week) from fishing, followed by fish procurement and marketing sector, and brackishwater aquaculture (shrimp farming). Similar kind of trend was noticed when all the enterprises were taken into consideration (Table 4). In total, the average income per week was highest for the fishers under marine sector $(₹ 14,679)$. It was lowest in the case of reservoir fisheries (₹1,700 per week). Apart from their income, majority

Table 3. Incidence of common diseases among adult (male and female) (on annual basis)

\begin{tabular}{|c|c|c|c|c|c|c|c|c|c|c|c|c|}
\hline \multirow{3}{*}{ Diseases } & \multicolumn{12}{|c|}{ Sectors } \\
\hline & \multicolumn{3}{|c|}{$\begin{array}{l}\text { Brackishwater } \\
\text { aquaculture (shrimp } \\
\text { farming) }\end{array}$} & \multicolumn{2}{|c|}{$\begin{array}{l}\text { Freshwater } \\
\text { aquaculture }\end{array}$} & \multicolumn{2}{|c|}{ Reservoir fisheries } & \multicolumn{2}{|c|}{$\begin{array}{l}\text { Fish procurement and } \\
\text { marketing }\end{array}$} & \multicolumn{3}{|c|}{ Marine fisheries } \\
\hline & M & $\mathrm{F}$ & & M & $\mathrm{F}$ & $\mathrm{M}$ & $\mathrm{F}$ & $\mathrm{M}$ & $\mathrm{F}$ & & M & $\mathrm{F}$ \\
\hline \multicolumn{13}{|l|}{ Present status } \\
\hline Fever/flu & 0.45 & 0.43 & & 0.48 & 0.68 & 0.25 & 0.35 & 0.96 & 1 & & 0.96 & 1 \\
\hline Body aches & 0.5 & 0.49 & & 0.94 & 0.98 & 0.10 & 0.56 & 0.028 & 0.052 & & 0.028 & 0.052 \\
\hline Diarrhoea & 0.07 & 0.02 & & 0.38 & 0.78 & 0.23 & - & NIL & NIL & & NIL & NIL \\
\hline $\begin{array}{l}\text { Gastro-enteric } \\
\text { disease }\end{array}$ & 0.41 & 0.35 & & NIL & NIL & NIL & NIL & NIL & NIL & & NIL & NIL \\
\hline Skin disorder & 0.05 & 0.03 & & 0.68 & 0.8 & NIL & NIL & NIL & NIL & & NIL & NIL \\
\hline $\begin{array}{l}\text { Reproductive } \\
\text { disorder }\end{array}$ & NIL & NIL & & NIL & NIL & NIL & NIL & NIL & NIL & & NIL & NIL \\
\hline \multicolumn{13}{|l|}{ Past status } \\
\hline Fever/flu & 6.91 & 7.16 & 3.5 & & 3.91 & 3.5 & 3.91 & 16.10 & 18 & 20.08 & & 21 \\
\hline Body aches & 7.41 & 7.5 & 2.75 & & 3.58 & 2.75 & 3.58 & 0.58 & 2.18 & 0.58 & & 1.08 \\
\hline Diarrhoea & 8.08 & 8.25 & 4.08 & & NIL & 4.08 & NIL & NIL & NIL & NIL & & NIL \\
\hline $\begin{array}{l}\text { Gastro-enteric } \\
\text { disease }\end{array}$ & 8.16 & 8.25 & NIL & & NIL & NIL & $\mathrm{NIL}$ & $\mathrm{NIL}$ & NIL & NIL & & NIL \\
\hline Skin disorder & 7.33 & NIL & 3.83 & & 4.08 & 3.83 & 4.08 & NIL & NIL & NIL & & NIL \\
\hline $\begin{array}{l}\text { Reproductive } \\
\text { disorder }\end{array}$ & NIL & NIL & 4.08 & & NIL & 4.08 & NIL & NIL & NIL & NIL & & NIL \\
\hline
\end{tabular}

Table 4. Income profile of the respondents (₹ per week)

\begin{tabular}{|c|c|c|c|c|c|c|}
\hline \multirow{2}{*}{ Sector } & \multicolumn{6}{|c|}{ Enterprise } \\
\hline & Fishery & Labour & Agriculture & Business & Others & Total \\
\hline Brackishwater aquaculture (shrimp farming) & 1153.84 & 384.6 & 384.6 & 480.76 & -- & 2019.23 \\
\hline Freshwater aquaculture & 865.38 & 192.30 & 384.61 & 384.61 & -- & 1730.76 \\
\hline Reservoir fisheries & 400.00 & 900.00 & 400.00 & -- & -- & 1700.00 \\
\hline Fish procurement and marketing & 2115.15 & 201.92 & -- & 251.15 & -- & 2550.65 \\
\hline Marine fisheries & 11223.08 & -- & -- & 2305.76 & 1150 & 14678.84 \\
\hline ANOVA & F value: $1.90 *$ & & & & & \\
\hline
\end{tabular}

\footnotetext{
*Indicate the significant difference in income among sub-sectors at $15 \%$ level of probability
} 
of the fishers availed loans to purchase craft/gear and other fishing related equipment, to manage marriage expenses and to construct houses. Owing to the low income of fishers engaged in reservoir fisheries, the likelihood of their availing loans was less as compared to other sectors. Around $50 \%$ of them reported that they availed loan for marriage expenses. Table 4 also clearly indicated that those sub-sectors engaged in regular activities and where seasonal factors do not play a major role, income of the respondent families was found to be relatively higher in comparison to the sectors which could ensure income depending upon the season and level of gestation period for fish culture (Ponnusamy and Gupta, 2007; 2009). Hence, schemes related to social development need to be given major focus among fishers engaged in inland fisheries, especially reservoir and freshwater aquaculture.

Table 5 furnishes the indices for different dimensions viz., health, literacy and income of the fishers as well as the composite FDI. It is explicit from the table that marine sector ranked first followed by freshwater aquaculture and fish procurement and marketing sector. High income for the marine sector and a relatively higher weightage (37\%) to the income dimension played a major role for its FDI score. In the case of health, freshwater aquaculture took the top score, whereas, in literacy dimension, reservoir fisheries ranked first. Studies on the socio-economic profile of fishermen by Bihari et al. (1999), Balasubramaniam and Braj Mohan (2002), Balasubramaniam et al. (2003) and Swathilekshmi (2011) indicated the need for strengthening of fisheries extension services to augment the socio-economic status of marine fisherfolk.

Results of the study suggest that, facilitating the availability of institutional financial support like micro-credit for reservoir and freshwater fisheries by further strengthening self help groups (SHGs) and regulation of fish marketing through institutional interventions including organised markets in urban and peri-urban areas will pave way for development. In addition, provision of transportation vehicles, iceboxes, refrigerators; imparting vocational training for fisherwomen to undertake household income generating activities during dry/off season, arrangement of employment opportunities during fishing holidays; regulation of public distribution system (PDS) and supply of the basic food items and fuel (like kerosene and LPG) as well as provisional supply of rural infrastructure shall lead to general societal development. Altogether, a multi-dimensional approach is needed for enhancing the level of income and employment generation of the fishers to match with the development of the rest in the society.

Table 5. Fishers development index (FDI) for different sectors

\begin{tabular}{llllll}
\hline \multirow{2}{*}{ Sectors } & \multicolumn{3}{c}{ Index } & FDI by expert opinion weights & Development category \\
\cline { 2 - 4 } & Health & Literacy & Income & Low \\
Brackishwater aquaculture (shrimp farming) & 0.667 & 0.453 & 0.080 & 0.385 & Moderate \\
Freshwater aquaculture & 0.750 & 0.640 & 0.008 & 0.443 & Low \\
Reservoir fisheries & 0.483 & 0.778 & 0.000 & 0.393 & Moderate \\
Fish procurement and marketing & 0.567 & 0.474 & 0.188 & 0.399 & High \\
Marine fisheries & 0.283 & 0.486 & 1.000 & 0.609 & \\
\hline
\end{tabular}

\section{Acknowledgements}

The authors acknowledge the financial support given by the Department of Animal Husbandry Dairying and Fisheries (DADF) for the project entitled, "An assessment of literacy, income and health status of fishers in India".

\section{References}

Ayyappan, S. and Biradar, R. S. 2004. Indian fisheries: Looking ahead, Current scenario and future needs of Indian fisheries.Decennial publication. Forum of Fisheries Professionals, Visakhapatnam, p. 1-4

Ayyoob, K. C., Krishnadas, M. and Kaleel, F. M. H. 2013. Intraregional disparities in the agriculture development of Kerala. Agric. Update, 8: 103-106.

Balasubramaniam, S., Remesan, M. P. and Nikita Gopal. 2003. Fish productivity and associated factors of fishermen. Indian J. Ext. Edu., 39(1\&2): 74-79.
Balasubramaniam, S. and Braj Mohan 2002. Group attributes of artisanal fishermen. Indian J. Ext. Edu., 38 (3\&4).

Bihari Bankey, Balasubramaniam, S., Braj Mohan. and Kandoran, M. K. 1999. Socio-economic status of marine fishermen in 2 fishing villages of Orissa. Indian J. Ext. Edu., 38 (3\&4).

DADF 2003. Livestock census 2003, Department of Animal Husbandry, Dairying and Fisheries, Ministry of Agriculture and Farmers Welfare, Government of India.

Jhingan, M. L. 2012. The economics of development and planning, $39^{\text {th }}$ edn. Vrinda Publications, $689 \mathrm{pp}$.

MoF 2015. Economic survey, 2014-15. Department of Economic Affairs, Ministry of Finance, Government of India.

Ponnusamy, K. and Jancy Gupta 2009. Livelihood contribution, prospects and problems of aquaculture in integrated farming systems. Indian. J. Fish., 56(4): 317-322. 
Ponnusamy, K. and Jancy Gupta 2007 Fisheries based farming system for sustainable livelihood of coastal farmers. Indian. J. Fish., 54(3): 327-331.

Rama Rao, D., Agrawal, R., Nanda, S. K., Awasthi, I. C., Joshi, G. P., Bhattacharya, S. and Indra Kumar, D. 2011. Assessment of future human capital requirements in agriculture and allied sectors. NAIP Project Report, National Academy of Agricultural Research Management, Hyderabad and Institute of Applied Manpower Research, Delhi, India, $370 \mathrm{pp}$.

Sathiadhas, R., Shyam, S. Salim and Narayanakumar, R. 2014. Livelihood status of fishers in India. Central Marine Fisheries Research Institute, Kochi, 348 pp.

Swathilekshmi, P. S. 2011. Livelihood and level of aspiration of coastal fisherfolk of Tamil Nadu. Indian J. Social Res., 52(1): 31-54. 